\title{
Typology of Business-Related Fake News Online: A Literature Review
}

\author{
Marko Selakovic ${ }^{1 *}$, Anna Tarabasz ${ }^{2}$, Monica Gallant ${ }^{3}$ \\ ${ }^{1,2,3}$ S P Jain School of Global Management, Block 5, Academic City, P.O. Box 502345, Dubai, UAE
}

\begin{abstract}
Objective - This review paper discusses the emergence of scholarly articles related to the typology and classification of fake news and offers solutions for identified gaps, such as unstandardized terminology and unstandardized typology in the field of fake news-related research. Typology of fake news is a critical topic nowadays: recently emerged fake news needs to be categorized and analyzed in a structured manner in order to respond appropriately.

Methodology/Technique - Based on the systematic review of literature identified in scientific databases, different typologies of fake news have been identified and a new typology of business-related fake news online has been proposed. New typology of business-related fake news online is based on factors such as level of facticity, intention to deceive and financial motivation.

Findings and novelty - Content analysis of 326 articles containing terms related to the typology of fake news and classification of fake news indicates that the term "typology of fake news" is predominantly used in management, marketing and communications research, while the term "classification of fake news" is predominantly used in the information technology research. The content analysis also indicates the recent emergence of the topic of typology and classification of fake news in academic research, revealing that all articles related to these topics have been published on or after 2016. In addition to the contribution by presenting comprehensive typology of business-related fake news online, this paper also provides recommendations for future research and improvements related to the typology of fake news, emphasizing business-related fake news and fake news spread in the digital space.
\end{abstract}

Type of Paper: Review

JEL Classification: M31, M39.

Keywords: Fake News; Crisis Communications; Online Communications; Digital Marketing; Management Research; Marketing Research

Reference to this paper should be made as follows: Selakovic, M; Tarabasz, A; Gallant, M. (2020). Typology of Business-Related Fake News Online: A Literature Review, J. Mgt. Mkt. Review 5(4) 234 - 243. https://doi.org/10.35609/jmmr.2020.5.4(5)

\section{Introduction}

Misinformation and manipulation in the media are well-known phenomena. However, misinformation and manipulation in the digital space came on the map with the development of Internet 2.0 and increase of the relevance of user-generated content in Internet 3.0 and marketing 3.0 era (Tarabasz, 2013). Web 3.0 and Meta Web introduced a new myriad of available solutions and opportunities (Tarabasz, 2013).

\footnotetext{
* Paper Info: Revised: October 29, 2020

Accepted: December 31, 2020

Corresponding author: Marko Selakovic

E-mail: marko.selakovic@spjain.org

Affiliation: S P Jain School of Global Management, Dubai, UAE
} 
Smart technologies and integration networks of Web 4.0, with an ability to detect intentions and goals of the users and offer solutions based on users` preferences and habits (Benhaddi, 2017) are opening an entirely new dimension of the social media: digital identity becomes an integral part of the identity of Internet users. After the 2016 elections in the United States, fake news became massively investigated and an extremely popular phenomenon (Wynne \& Wint, 2019), being named as word of the year by both the American Dialect Society and Collins Dictionary (Anderson, 2018). Scientific circles followed this trend, and hundreds of articles have been published in the last several years.

Although fake news is a topic that emerged recently in marketing, communication and management research, history is providing numerous examples of how fake news is spread and how fake news played its role even in the time of the pre-press era. False stories and rumours are likely to have existed as long as humans have lived in groups (Burkhardt, 2017; Shu, Sliva, Wang, Tang \& Liu, 2017).

Internet and social media, as highly interactive platforms, enable two way-communication and content generation which was unprecedented in history. In the past, the media were decisive about content that should be presented, and what public impact it might have (Giessen, 2015). Nowadays, user-generated content presented an opportunity for single Internet users to reach large audiences in the same way as content generated from the traditional mass-media.

Although the development of modern communication methods opened wide horizons of opportunities that companies can use for communication of brands with the customers (Bacik et al., 2018), this development also created a suitable environment for massive production and proliferation of fake news. Over time, the phenomenon of online-generated fake news attracted more attention from the public and the threat of fake news and disinformation has become very realistic nowadays (Kažys, 2018). Consequently, researchers and academics across the globe started to investigate the generation, dissemination, detection and impact of the fake news in an intensive manner; however, the body of the available research is still recent and inconsistent. From the body of literature available nowadays, it is obvious that fake news is, among other characteristics, deemed to be a frequent generator of crises, or if spread in the digital space, a generator of social media crisis challenges (Michele Ewing \& Lambert, 2019). Moreover, there is very limited evidence that would enable both academics and practitioners to understand what types of fake news can be found in the digital space. The pool of evidence is even smaller when the topic of fake news online is contextualized within business communications. At the same time, term "fake news" is minutely depicted within political communications, becoming not only matter of research, but also a trend in political debates (Egelhofer \& Lecheler, 2019). However, from organizational and business perspective, phenomenon of fake news needs to be further examined.

\section{Literature Review}

\subsection{Definition of the Fake News}

Bakir and McStay (2018) in a very broad scope, defined fake news as either wholly false or containing deliberately misleading elements incorporated within the content or context. The core of this definition contextualizes fake news as false or misleading. However, it does not provide additional inputs related to the nature of the fake news and sources of the appearance: it broadly covers both context and content. The definition of Allcott and Gentzkow (2017, p. 213) describes fake news "to be news articles that are intentionally and verifiably false and could mislead readers". This description offered by Allcott and Gentzkow (2017) includes readers as a key factor. Thus, it can be concluded that fake news needs to be published in order to be perceived under the category. This consideration, if contextualized further from theoretical and semantical perspective, excludes any unpublished content, such as word of mouth or rumours from the category of fake news. This is in line with the definition of fake news as "fabricated information that mimics news media content in form but not in organizational process or intent" (Lazer et al., 2018, p. 1094). Sukhodolov (2017) defines fake news as "message, stylistically created as current news, but false completely 
or partially". However, there is historical evidence that might dispute the limitations of definitions provided by Allcott and Gentzkow (2017), Sukhodolov (2017) and Lazer et al. (2018): according to Burkhardt (2017), fake news had been evidenced even prior to the appearance of the print media, finding their place in books or historical remarks: differently, definitions of Allcott and Gentzkow (2017) and Lazer et al. (2018) are limited to the news articles only.

Some researchers provide very narrow and focused definitions of fake news, putting fake news primarily in the context of social media. Pennycook and Rand (2019) suggested in their research that fake news consist primarily of highly conspicuous fabricated claims that are created to spread on social media. However, social media - limited definitions of the fake news, such as one proposed by Pennycook and Rand (2019), are in opposite with considerations of numerous authors (Burkhardt, 2017; Shu, Sliva, Wang, Tang \& Liu, 2017; Lazer et al, 2018; Tandoc Jr, Lim \& Ling, 2018) that fake news is initially much older and significantly broader phenomenon, observed both by context and place of appearance.

Literature sources also analyse in detail the nature of fake news and if all misinformation and disinformation should be considered as fake news. Further, the literature sources offer a clear distinction between misinformation and disinformation. Wardle (2017) described misinformation as an inadvertent sharing of false information, whereas disinformation is created with a deliberate character - to create and share the information known to be false. Although both categories are fake news for Wardle (2017), Albright (2016) differentiates misinformation from false news, labelling as fake news only the content created deliberately. At the same time, McCorkindale (2019) demonstrated similar viewpoints as Wardle (2017). In this article, misinformation is clearly distinguished from disinformation: misinformation is false information that is spread, while disinformation is deliberately misleading or false. According to McCorkindale (2019), both misinformation and disinformation should be qualified as fake news. Similar standpoint is demonstrated by Lazer et al. (2018), who indicated that fake news is overlapping with other information disorders, considering and defining disinformation as "false information that is purposely spread to deceive people" and misinformation as "false or misleading information" (ibidem, p. 1094). Allcott and Gentzkow (2017) provided another type of distinction, suggesting that fake news has several close cousins that cannot be classified as fake news, such as unintentional reporting mistakes, rumours that do not originate from the particular article, conspiracy theories, satires unlikely to be mis-constructed, false statements given by politicians and reports that are slanted or misleading, but not outrightly false.

\subsection{Review of typologies of the fake news}

Considered from both the academic and applied perspective, the existence of typology is important, because it aids in understanding the phenomenon of fake news, and at the same time provides structured overview to the possible future directions in fake news evolvement and emergence.

Sanders and Jones (2018) offered a typology of the categories of the fake news, such as:

". False connection: When headlines, visuals or captions don't support the content.

- Misleading content: Misleading use of information to frame an individual or issue.

- False context: When genuine content is shared with false contextual information.

- Imposter content: When genuine sources are impersonated.

- Manipulated content: When factual information or imagery is manipulated to deceive.

- Fabricated content: New content that is $100 \%$ false, designed to deceive and do harm" (ibidem, p. 344).

In addition to this classification, a news satire or news parody is described as another type of fake news by numerous authors (Wardle, 2017; Bakir \& McStay, 2018; Tandoc Jr, Lim \& Ling, 2018).

Tandoc Jr, Lim and Ling (2018) offered a typology where photo manipulation, news fabrication, news satire, news parody, propaganda and advertising and public relations (also marked as native advertising) are identified as key groups or types of fake news. Tandoc Jr, Lim \& Ling (2018) identify the author`s immediate intention to deceive and level of facticity as core factors to be observed. Native advertising and propaganda are having a high level of facticity paired with high author`s intention to deceive, whereas manipulation and 
fabrication are having a low level of facticity in par with high author`s intention to deceive. News satire has a high level of facticity and low intention to deceive, while news parody has both a low level of facticity and low intention to deceive. Considerations and typology conclusions of Tandoc Jr, Lim and Ling (2018) are based on the analysis of 34 scholarly articles published that used the term "fake news". The classification offered is shown in the table below (Table 1):

\begin{tabular}{|c|c|c|}
\hline \multirow{2}{*}{ Level of facticity } & \multicolumn{2}{|c|}{ Intention to deceive } \\
\cline { 2 - 2 } & High & Low \\
\hline \multirow{2}{*}{ High } & Native advertising & \multirow{2}{*}{ Satire } \\
\cline { 2 - 2 } & Propaganda \\
\hline \multirow{2}{*}{ Low } & Fabrication & Parody \\
\cline { 2 - 2 } & Manipulation & \\
\hline
\end{tabular}

Table 1: Typology of fake news by Tandoc Jr, Lim \& Ling (2018)

Verstraete, Bambauer, and Bambauer (2017) offered another classification of fake news based on two variables: the author's tendency to deceive readers and whether the payoff is motivated by financial interests or not. However, considerations of Verstraete, Bambauer and Bambauer (2017) are not interpreted in the broader context and did not go beyond the basic typology, without specific details.

Sukhodolov (2017) suggested very detailed classification that included numerous parameters, such as true/false information ratio, characteristics of the event, persons involved, goals of news creators and publishers and authenticity of the news towards the audience. Sukhodolov (2017) supported his classification with numerous examples almost strictly related to fake news in the political sphere. Disinformation, hoax, misbehaviour, misinformation, and rumours are described as types of fake news spread online (Cardoso Durier da Silva, Vieira and Garcia, 2019). However, the typology elaborated by Cardoso Durier da Silva, Vieira and Garcia (2019) is analyzing a narrow niche of the fake news published in the digital space. This classification does not provide additional insights neither about the level of facticity nor about the intention of the author to deceive the audience exposed to the fake news.

Outside of the scholarly typologies, professional societies are also attempting to create a comprehensive typology of fake news. EAVI - the European Association for Viewers Interests listed ten different types of fake news, classifying them by type and by impact and motivation marks. The list includes propaganda, partisan, clickbait, conspiracy theory, sponsored content, pseudoscience, satire and hoax, misinformation, error and bogus (EAVI, 2017). Although EAVI (2017) is providing a very detailed overview, the described typology is not fully applicable in the business context: some news included into EAVI (2017) classification, such as fake partisan news, are entirely oriented towards the political audiences (Pennycook \& Rand, 2019) and thus cannot be fully interpreted in the business context. Nowadays, theoretical concepts recognize the possibility of mixing and overlapping different types of fake news and their role in creation of post-truth world. Although journalism has reputation of technology of truth, circumstances and conditions nowadays are considerably different, including the possibility to generate new types of fake news (Waisbord, 2018).

Motivation for creating the fake news has also been considered as relevant in business communications: the key reason to create the fake news is to impact public opinion on behalf of a person or organization on the topic of the given choice (Sanders \& Jones, 2018). This is important because content impacts perception of both the organization/brand and other market participants in the eyes of its customers (Kliestik et al., 2018). Further, brands tend to be vulnerable towards fake news (Braun \& Eklund, 2019; Borges-Tiago et al., 2020). Although organizations normally benefit from responsible behaviour (Kel'chevskaya, Chernenko \& Popova, 2017), both theory and practice confirm that brands can also propagate fake news by themselves to undermine the reputation of their competitors (Berthon, Treen \& Pitt, 2018). In the business context, this aspect might be considered as indirectly connected with profit and not only with the reputation or business development; hence, this can be contextualized as indirect financial motivation. At the same time, creation of the fake news can be directly connected with financial benefits (Verstraete, Bambauer \& Bambauer, 2017). 
In the business sector, fake news is having significant capability to contribute to the increase of company stock price and asset values (Laouiti, Msolli \& Ajina, 2016). In such cases, creation of fake news is associated with direct financial motivation.

\section{Research Methodology}

A systematic review of literature has been used to identify the scholarly articles that deal with the typology and classification of fake news. Thorough search of the databases for the articles included JSTOR, Elsevier and Google Scholar databases.

The database search has been performed for the idiomatic keyword terms: "typology of fake news", "fake news typology", "classification of fake news", and "fake news classification". The search has been performed for each scientific database separately for each keyword. Search results have been compared and compiled to extract complete information about the available body of literature. Based on the outcome of the keyword search, articles have been grouped by keywords and a detailed analysis of comprehensive typologies of fake news has been provided in the literature review.

Content analysis has been performed to understand the nature and scientific scope of different scholarly articles published in the available sources that are containing any of the idiomatic keyword terms described above. The content analysis has been deployed with the aim to answer the following questions:

Q1: What is the scientific field of the scholarly article?

Q2: Is there comprehensive typology and/or classification offered?

Q3: When the scholarly article has been published?

Four sub-groups of articles, following the terms "Typology of fake news", "fake news typology", "classification of fake news", and "fake news classification" have been created. Based on the outcomes of content analysis, the articles have been classified for each sub-group under one of the following scientific field categories: Marketing / communication / management research, Information technology research, Law research, and Linguistics research.

A comparative analysis was implemented to understand if there is an interdependence between the terminology used and the scientific scope of the scholarly research papers identified through the database search. Based on the findings of this research, conclusions and recommendations for the future have been drawn.

\section{Results and discussion}

Systematic review of the available literature sources indicates there are no universally accepted classifications and typologies of fake news, irrespective of its nature and place of occurrence. Even further, numerous researchers in the fields of marketing, communications and management are providing classifications that vary by nature and context, as described in the literature review. Across disciplines, no typology of fake news offers comprehensive combination of factors such as intention to deceive, level of facticity and motivation for sharing business-related fake news online.

To illustrate how emerging, unexplored and unstructured classification and typology of fake news are, it might be worth to note that profound scientific database search did not return any results for the terms "typology of fake news", "classification of fake news", "fake news typology" and "fake news classification", when the search was performed for the research papers, articles and books published before 2016. This is a clear indicator that all the publications describing the typology and possible classifications of the fake news appears to be entirely new in the academic terms.

The content analysis based on search of scientific databases JSTOR, Elsevier and Google Scholar for the period from January 2016 till June 2020 returned 326 results for the mentioned idioms, with the following distribution (Figure 1): 


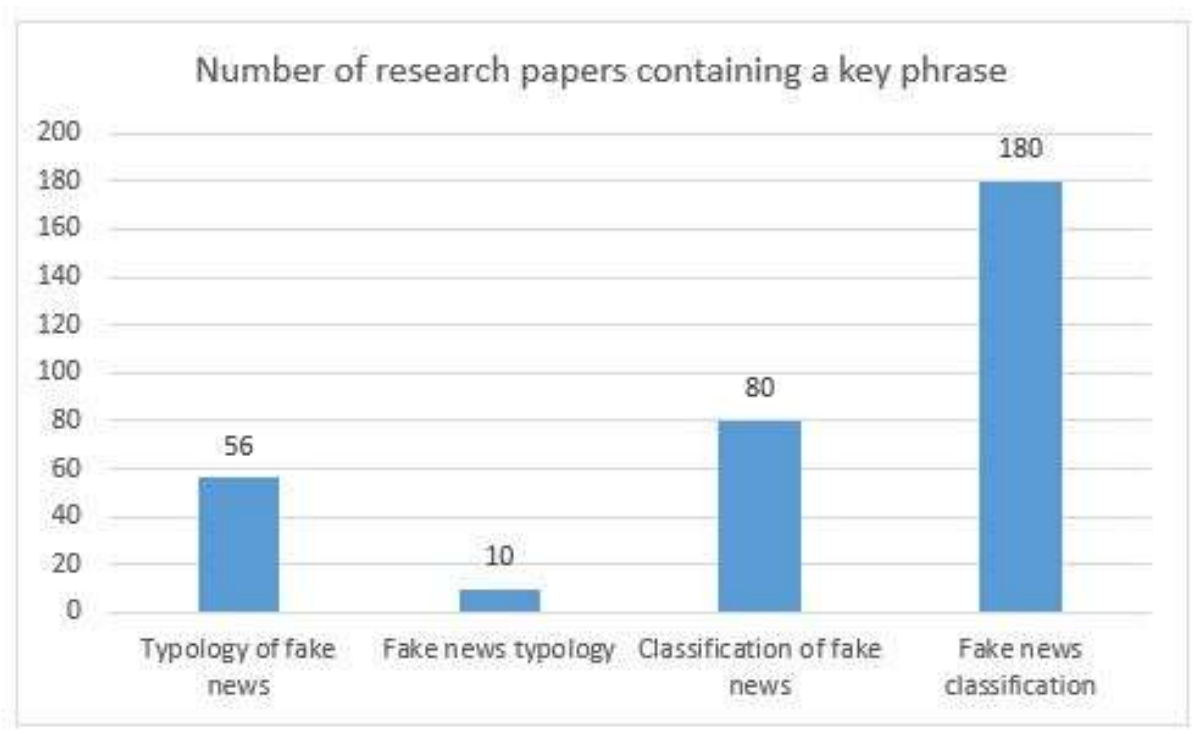

Figure 1: Number of research papers containing the phrases related to typology and classification of fake news

This finding confirms that topic of fake news classification is an emerging topic in the scientific research. Moreover, the terminology used to describe different types of fake news seems to be still unstandardized and open for various interpretations.

It is critical to recognize and understand both nature and context of different terminologies identified within the available body of the literature. The content analysis indicates that terms "Fake news typology" and "Typology of fake news" are predominantly present in the marketing, management and communication research $(92.4 \%$ of the mentions of these phrases have been identified in the research papers related to marketing, management and communication), whereas terms "Classification of fake news" and "Fake news classification" are mostly related to the research performed in the field of the information technology software solutions for fake news detection $(78.1 \%$ of the mentions of these phrases have been identified in the research papers related to the information technology).

Study of classification and typology of fake news, in the context of definition of types of fake news within the available research in the fields of linguistics and law is returning very limited results (see Table 2).

\begin{tabular}{|c|c|c|c|c|}
\hline \multirow{2}{*}{ Phrase } & \multicolumn{2}{|c|}{ Number of research papers by scientific field } \\
\cline { 2 - 5 } & $\begin{array}{c}\text { Management / } \\
\text { Marketing / } \\
\text { Communications }\end{array}$ & IT & Linguistics & Law \\
\hline Typology of fake news & 51 & 4 & 0 & 1 \\
\hline Fake news typology & 10 & 0 & 0 & 0 \\
\hline Classification of fake news & 20 & 55 & 3 & 2 \\
\hline Fake news classification & 17 & 158 & 5 & 0 \\
\hline TOTAL & $\mathbf{9 8}$ & $\mathbf{2 1 7}$ & $\mathbf{8}$ & $\mathbf{3}$ \\
\hline
\end{tabular}

Table 2: Number of research papers containing the phrases, classified by the scientific discipline

The findings indicate that term "typology" is connected with the communications / marketing or management research of the fake news, whereas term "classification" is associated with the information technology research of the fake news. At the same time, findings of the study demonstrate that terminology 
related to the fake news typology and fake news classification is more present in the information technology research than in the management, marketing or communications research.

The results of the systematic review and content analysis indicate that term "Typology of fake news" is almost exclusively reserved for the research in the field of marketing, communication and management. At the same time, fake news-related research in the field of the information technologies is predominantly focused on the usage of terms "classification of fake news" and "fake news classification".

All 326 scholarly research articles dealing with either classification or typology of fake news identified through the systematic review of literature appeared on or after 2016. This finding is in strong correlation with considerations that fake news emerged as a research topic after 2016 (Wynne \& Wint, 2019).

\section{Managerial implications}

Although fake news research is emerging across the academic community, the research related to the fake news classification in the field of the information technologies is more present in the body of available literature than the research related to the fake news typology in the fields of marketing, communications and management. Interestingly, only limited number of scholarly articles that are considering fake news typology or classification in entirely legal or linguistic context is present in the body of available literature.

Lack of globally standardized definition of the fake news typology identified through the systematic review of the literature is understandable: fake news research is still emerging in all fields. At the same time, appearance of new media, especially in the digital space, is opening space for creation of new types of fake news. The typology of fake news is critical both for scholarly researchers and practitioners: it should help them to understand and classify different types and groups of fake news. Further, the typology should help scholarly researchers and practitioners to understand the characteristics of different types of fake news and to connect them with various factors and mechanisms that are influencing their occurrence. Thus, new comprehensive typology of fake news related to business and spread online, has been created based on the systematic review: types of business-related fake news described in the literature have analyzed in the context of three factors relevant for sharing fake news online and described in the literature: level of facticity, intention to deceive and financial motivation. A comprehensive typology matrix is shown in Table 3 .

\begin{tabular}{|c|c|c|c|c|c|c|}
\hline Type of fake news & \multicolumn{2}{|c|}{ Level of facticity } & \multicolumn{2}{c|}{ Intention to deceive } & \multicolumn{2}{c|}{ Financial motivation } \\
\hline & High & Low & High & Low & Direct & Indirect \\
\hline False connection & & & & & & \\
\hline Misleading content & & & & & & \\
\hline False context & & & & & & \\
\hline Imposter content & & & & & & \\
\hline Manipulated content & & & & & & \\
\hline Fabricated content & & & & & & \\
\hline News satire & & & & & & \\
\hline News parody & & & & & & \\
\hline
\end{tabular}

Table 3: Business typology of fake news online (construct of the authors, based on Sanders \& Jones, 2018; Tandoc Jr, Lim \& Ling, 2018)

Business-related fake news is substantially connected with the indirect financial benefit for the organization, either through building and boosting its own brand, or through derogation and defamation of the competitors. Further, manipulation, fabrication and false contextualization might be connected with the direct financial benefits for an organization, such as increase of the market share, enhancing sales or increase of the stock price and other asset values (Laouiti, Msolli \& Ajina, 2016). 


\section{Conclusion}

Within this article, a typology of business-related fake news online, based on the level of facticity and intention to deceive, possibly in combination with different motivational factors, has been offered. The typology provides a general and comprehensive overview, as it deals with the categories that are not related to the type of online media: it is based on the characteristics of the fake news and motivation factors rather than on the channels used to spread them. The proposed typology provides a strong contribution to the fake news research by business contextualization and an overview of business-related fake news spreading in the digital space. The new typology is an enabler for scholarly researchers and industry professionals to study fake news more deeply and make comparisons using different factors. In a future research, the typology proposed in this research paper can be further examined and fine-tuned through an exploratory research that could include management, marketing and communication practitioners who face fake news in their everyday business operations.

The research indicates that in future communication, marketing and management research related to fake news, the term "typology of fake news" should be used. A more stringent approach to the terminology will enable a clear distinction of fake news typology in marketing, management or communications context from fake news classification, used in the information technology research.

Fake news is an emerging topic in the scholarly research. The same might be concluded for the typology of fake news. With the future evolvement and development of fake news research in the business sphere, it will be possible to further upgrade this research and suggest new and updated typologies of business fake news online. With the evolvement of Internet and online communication channels, new types of fake news may evolve as well: thus, the typology of business-related fake news should be based on the nature of the news - their level of facticity and intention to deceive, as well as on financial benefits for the organizations that are involved in spreading fake news in the digital space.

Despite all efforts, fake news will be present around us: fake news is an idiosyncratic phenomenon of the digital world. The more research is deployed, the better are the chances to understand and counter the effects of fake news. Thus, this research is just a starting point: more work that will provide better understanding of fake news is expected in the future.

\section{Acknowledgement}

This paper is based on a research project carried out as part of doctoral thesis research. Thus, this paper should be considered as part of doctoral thesis work of candidate Marko Selakovic. The doctoral thesis research, including the research project described in this paper, has been performed at S P Jain School of Global Management - Dubai campus.

\section{References}

Albright, J. (2017). Welcome to the era of fake news. Media and Communication, 5(2), 87-89. https://doi.org/10.17645/mac.v5i2.977

Allcott, H., \& Gentzkow, M. (2017). Social media and fake news in the 2016 election. Journal of economic perspectives, 31(2), 211-36. DOI: 10.1257/jep.31.2.211

Anderson, K. E. (2018). Getting acquainted with social networks and apps: combating fake news on social media. Library Hi Tech News. https://doi.org/10.1108/LHTN-02-2018-0010

Bacik, R., Fedorko, R., Nastisin, L., \& Gavurova, B. (2018). Factors of communication mix on social media and their role in forming customer experience and brand image. Management \& Marketing. Challenges for the Knowledge Society, 13(3), 1108-1118. https://doi.org/10.2478/mmcks-2018-0026

Bakir, V., \& McStay, A. (2018). Fake news and the economy of emotions: Problems, causes, solutions. Digital journalism, 6(2), 154-175. https://doi.org/10.1080/21670811.2017.1345645 
Benhaddi, M. (2017, April). Web of Goals: A Proposal for a New Highly Smart Web. In ICEIS (2) (pp. 687-694). DOI: 10.5220/0006250306870694

Berthon, P., Treen, E., \& Pitt, L. (2018). How truthiness, fake news and post-fact endanger brands and what to do about it. Marketing Intelligence Review, 10(1), 18-23. https://doi.org/10.2478/gfkmir-2018-0003 |

Borges-Tiago, T., Tiago, F., Silva, O., Guaita Martínez, J. M., \& Botella-Carrubi, D. (2020). Online users' attitudes toward fake news: Implications for brand management. Psychology \& Marketing, 37(9), 1171-1184. https://doi.org/10.1002/mar.21349

Braun, J. A., \& Eklund, J. L. (2019). Fake news, real money: Ad tech platforms, profit-driven hoaxes, and the business of journalism. Digital Journalism, 7(1), 1-21. https://doi.org/10.1080/21670811.2018.1556314

Burkhardt, J. M. (2017). Combating fake news in the digital age (Vol. 53, No. 8, pp. 5-9). American Library Association.

Cardoso Durier da Silva, F., Vieira, R., \& Garcia, A. C. (2019, January). Can machines learn to detect fake news? a survey focused on social media. In Proceedings of the 52nd Hawaii International Conference on System Sciences.

DOI:10.24251/HICSS.2019.332

EAVI - the European Association for Viewers Interests (2017, July 26). Infographic: Beyond Fake News - 10 Types of Misleading News. The European Association for Viewers Interests. https://eavi.eu/beyond-fake-news-10-typesmisleadinginfo/

Egelhofer, J. L., \& Lecheler, S. (2019). Fake news as a two-dimensional phenomenon: a framework and research agenda. Annals of the International Communication Association, 43(2), 97-116. https://doi.org/10.1080/23808985.2019.1602782

Giessen, H. W. (2015). Sustainable entrepreneurship and peculiarities of media-based learning. Entrepreneurship and Sustainability Issues, 2(3), 154. DOI:10.9770/jesi.2014.2.3(4)

Kažys, J. (2018). Climate Change Information on Internet By Different Baltic Sea Region Languages: Risks Of Disinformation \& Misinterpretation. Journal of Security \& Sustainability Issues, 7(4). https://doi.org/10.9770/jssi.2018.7.4(6)

Kelchevskaya, N.R., Chernenko, I.M., \& Popova, E.V. (2017). The influence of corporate social responsibility on the investment attractiveness of Russian companies. Economy of the region, 13 (1)., 157-169.

Kliestik, T., Kovacova, M., Podhorska, I., \& Kliestikova, J. (2018). Searching for key sources of goodwill creation as new global managerial challenge. Polish Journal of Management Studies, 17.

Lazer, D. M., Baum, M. A., Benkler, Y., Berinsky, A. J., Greenhill, K. M., Menczer, F., ... \& Schudson, M. (2018). The science of fake news. Science, 359(6380), 1094-1096. DOI: 10.1126/science.aao2998

Laouiti, M. L., Msolli, B., \& Ajina, A. A. (2016). Buy The Rumor, Sell The News! What About Takeover Rumors?. Journal of Applied Business Research (JABR), 32(1), 143-160. https://doi.org/10.19030/jabr.v32i1.9529

McCorkindale, T. (2019, June 20). Disinformation in Society Report. Institute for Public Relations. https://instituteforpr.org/ipr-disinformation-study/

Michele Ewing, A. P. R., \& Lambert, C. A. (2019). Listening In: Fostering Influencer Relationships to Manage Fake News. Public Relations Journal, 12(4), 1-20.

Pennycook, G., \& Rand, D. G. (2019). Lazy, not biased: Susceptibility to partisan fake news is better explained by lack of reasoning than by motivated reasoning. Cognition, 188, 39-50. https://doi.org/10.1016/j.cognition.2018.06.011

Sanders, A. K., \& Jones, R. L. (2018). Clicks at Any Cost: Why Regulation Won't Upend the Economics of Fake News. Business, Entrepreneurship \& Tax Law Review, 2(2), 339-358.

Shu, K., Sliva, A., Wang, S., Tang, J., \& Liu, H. (2017). Fake news detection on social media: A data mining perspective. ACM SIGKDD explorations newsletter, 19(1), 22-36. https://doi.org/10.1145/3137597.3137600

Sukhodolov, A.P. (2017). The phenomenon of "fake news" in the modern media space. Eurasian Cooperation: Humanitarian Aspects, (1)., 36-55.

Tandoc Jr, E. C., Lim, Z. W., \& Ling, R. (2018). Defining “fake news" A typology of scholarly definitions. Digital journalism, 6(2), 137-153. https://doi.org/10.1080/21670811.2017.1360143

Tarabasz, A. (2013). The use of social media in the Polish retail banking in the era of marketing 3.0. Studia Ekonomiczne, (150), 159-168.

Verstraete, M., Bambauer, D. E., \& Bambauer, J. R. (2017). Identifying and countering fake news. Tucson, AZ: The University of Arizona

Waisbord, S. (2018). Truth is what happens to news: On journalism, fake news, and post-truth. Journalism studies, 19(13), 1866-1878. https://doi.org/10.1080/1461670X.2018.1492881 
Wardle, C. (2017, February 16). Fake News. It's Complicated. First Draft. Medium. https://medium.com/1st-draft/fakenews-its-complicated-d0f773766c79

Wynne, H. E., \& Wint, Z. Z. (2019, December). Content Based Fake News Detection Using N-Gram Models. In Proceedings of the 21 st International Conference on Information Integration and Web-based Applications \& Services (pp. 669-673).DOI: 10.1145/3366030.3366116 